\title{
DETERMINANTES SOCIAIS E TERRITÓRIO EM SUA INTER-RELAÇÃO COM AS FAMÍLIAS E OS PROCESSOS DE SAÚDE-DOENÇA
}

SOCIAL DETERMINANTS AND TERRITORY IN THEIR INTERRELATION WITH FAMILIES AND

HEALTH-DISEASE PROCESSES

Carla Oliveira Jacques', Graziela Milani Leal ${ }^{2}$

RECEBIDO EM: 10/04/2017 / APROVADO EM: 10/05/2017

DOI: $10.5902 / 2317175826620$

\begin{abstract}
RESUMO
No contexto sócio-histórico de intervenção no processo de saúde-doença, apesar de todos os avanços no campo do marco legal, ainda figura como um desafio para a realidade brasileira a materialização e implementação integral dos princípios norteadores preconizados pelo Sistema Único de Saúde (SUS). Tensionados pelo contexto neoliberal que configura o papel do Estado em sua intervenção mínima e a intensificação das expressões da questão social, não raras vezes a responsabilidade por atender às demandas por proteção social recaem em uma culpabilização e estigmatização sobre as famílias. Dessa forma, este artigo busca problematizar o movimento de apreensão sócio-histórica do processo saúde-doença e sua relação com as famílias, sobretudo, sob a ótica de sua materialidade socioespacial e de seus determinantes sociais, mediadas por meio das políticas públicas. Assim, verifica-se que as famílias vêm assumindo as mais variadas configurações, figurando como um desafio a criação, implementação e avaliação de políticas públicas que de fato assegurem o acesso universal à saúde, frente a um contexto de privatização e comercialização - demonstrando a importância de considerar o território para além de seu espaço geográfico na apreensão de sua relação com os determinantes sociais do processo de saúde-doença.
\end{abstract}

Palavras-chave: Famílias; Saúde-doença; Determinantes Sociais; Território.

1 Graduanda em Serviço Social pela PUCRS. Bolsista CNPq.

2 Assistente Social Judiciária do Fórum da Comarca de Viamão. 
DETERMINANTES SOCIAIS E TERRITÓRIO EM SUA INTER-RELAÇÃO

COM AS FAMÍLIAS E OS PROCESSOS DE SAÚDE-DOENÇA

\begin{abstract}
In the brazilian socio-historical context of intervention in the health-disease process, despite all the advances in the field of the legal framework, it still poses as a challenge for the brazilian reality the materialization and integral implementation of the guiding principles recommended by Unified Health System (SUS). Tensioned by the neoliberal context that configures the role of the State into minimal intervention and the intensification of the expressions of social question, the responsibility for the demands of social protection often rests on a blame and stigmatization of the families. In this way, this article aims to problematize the movement of socio-historical apprehension of the health-disease process and the interrelation with families, especially from the perspective of socio-spatial materiality and social determinants, mediated by public policies. Therefore, it is verified that the families are assuming the most varied configurations, posing as a challenge the creation, implementation and evaluation of public policies that in fact ensure universal access to health, in the context of privatization and commercialization - demonstrating the importance of the category "territory" for beyond the concept of geographic space, in the apprehension of its interrelation with the social determinants of the health-disease process.
\end{abstract}

Keywords: Families; Health-disease; Social determinants; Territory.

\title{
1 Introdução
}

Ao se pensar a inter-relação entre saúde e família, é fundamental compreendê-la enquanto um processo dialético que acompanha os movimentos da realidade, que sofre determinação e influência do contexto social, cultural, político, econômico e estrutural, sendo espaço de produção e reprodução, que pode assumir diversas configurações de acordo com cada período histórico. A respeito das famílias, percebe-se que o nível de sua importância varia ao longo dos séculos, de modo que elas acabam por refletir as diferenças entre as classes sociais e evidenciar as mais diversas formas de organização da sociedade.

Em relação ao processo saúde-doença, verifica-se que um vasto caminho foi trilhado, havendo a construção de diferentes explicações e relações efetuadas ao longo dos séculos, que culminaram na reflexão de um conceito ampliado de saúde. Assim, neste estudo, busca-se problematizar o processo saúde-doença e sua relação com as famílias, sobretudo, com as que se encontram em situação de vulnerabilidade social, sob a ótica de sua materialidade socioespacial e de seus determinantes sociais, atentando às políticas públicas. Nesse cenário, ganha especial atenção a Política Nacional de Atenção Básica, a qual, tendo a centralidade na família, busca efetivar-se em nível territorial, onde se materializa o cotidiano vivido dos sujeitos.

Nesse sentido, é imperativa a consideração dos determinantes sociais para a compreensão do processo saúde-doença, sob pena de se fortalecer a falácia que culpabiliza e estigmatiza as famílias, transferindo a elas a responsabilidade por atender e superar suas próprias demandas - o que é estrutural e indissociável do modo como a sociedade capitalista se produz e 
reproduz. Sob esse aspecto, a dimensão socioespacial dos determinantes em saúde (DSS) ganha potencialidade, na medida em que a categoria território é apreendida para além de sua dimensão geográfica e, portanto, compreendida enquanto "território usado" (Santos, 1999) e enquanto processo relacional entre as famílias, seus modos de vida e suas condições sociais, sendo, ao mesmo tempo, condicionada e condicionante do processo de saúde-doença.

\section{Saúde e famílias: caminhos sócio-históricos}

Ao se revisitar a história de construção social das famílias em sua relação com os processos de saúde-doença, verifica-se que, no século XII, a principal função das famílias (RODRIGUES; ABECHE, 2005) era a proteção e a própria sobrevivência, de maneira que, para isso, as pessoas organizavam-se em aldeias, onde as fronteiras entre os grupos eram quase inexistentes, não havendo distinção entre eles, bem como entre a infância e a adultez. Nesse período, há o predomínio das interpretações mágico-religiosas que percebiam as doenças enquanto uma esfera sobrenatural, associada a fatores externos como o desejo de deuses ou espíritos.

Nesse contexto, ganham especial importância figuras como os sacerdotes, os pajés e as benzedeiras, a quem era atribuída a função de realizar a cura. Entretanto, com o apogeu da civilização grega, passa-se a entender a saúde e a doença enquanto resultados de processos naturais, descartando-se as explicações relacionadas ao mágico ou ao sobrenatural. A medicina hipocrática é, então, difundida, trazendo importantes contribuições por relacionar a saúde e a doença a fatores como o clima, o modo de vida, a alimentação e o ambiente, ressaltando a necessidade de haver equilíbrio entre o homem e o meio no qual ele vive. (BATISTELLA, 2007).

Não obstante, na Idade Média, o racionalismo perde espaço com o fortalecimento da igreja e a expansão do cristianismo, que reafirmava a relação intrínseca entre a doença e o pecado, havendo o retorno do pensamento religioso associado à explicação para a saúde e a doença. Conhecida como sendo a idade das trevas, nessa época histórica as epidemias e as pestilências assolaram a população, que passou a atribuir a responsabilidade pela cura aos religiosos, já que a doença era entendida como uma espécie de castigo de Deus necessário à purificação da alma e à remissão dos pecados. Ressalta-se, nessa fase, a função exercida pelos tribunais da Inquisição, sendo "desautorizadas todas as iniciativas de avanço no conhecimento das causas das doenças e até mesmo de sugestão de qualquer explicação que estivesse além da fé" (BATISTELLA, 2007, p. 37) -, o que se altera somente na Idade Moderna.

Com a emergência do movimento renascentista, tem-se a retomada da busca pelo saber científico e pelas explicações técnicas e racionais dos processos de saúde e de doença, ganhando espaços os estudos clínicos de observação, principalmente em relação à anatomia e à fisiologia humana. Ressaltam-se os 
DETERMINANTES SOCIAIS E TERRITÓRIO EM SUA INTER-RELAÇÃO

COM AS FAMÍLIAS E OS PROCESSOS DE SAÚDE-DOENÇA

avanços no campo cirúrgico e o surgimento da teoria miasmática, a qual associa a ausência e a precariedade de condições sanitárias às doenças infecciosas e aos surtos epidêmicos (MASTROMAURO, 2011). Ainda nesse período, tem-se a transição do modo de produção feudal para o modo de produção capitalista, em que a nova formatação social e de Estado vão ter importantes implicações para as mudanças nas concepções tanto de saúde e doença quanto de família.

Nesse sentido, verifica-se que, ao longo dos séculos $\mathrm{XV}$, XVI, e XVII, as principais funções das famílias alteram-se, uma vez que o importante, nesse período, era compor um arranjo familiar que tivesse como principal fim a proteção dos bens e a ampliação do patrimônio - o que ocorria principalmente por meio dos casamentos. Sendo predominantemente patriarcal, esse período histórico foi marcado pela não valorização da infância, de forma que o cuidado com os filhos era tido como indigno, sendo terceirizado às amas de leite. Estas normalmente eram de famílias camponesas que sobreviviam do trabalho no campo, onde os índices tanto de natalidade quanto de mortalidade infantil eram extremamente elevados, e as condições de vida, precárias (ARIÈS,1981).

A partir do final do século XVIII, com o advento da Revolução Industrial, há muitas mudanças que impactam o âmbito familiar e demarcam o início da separação entre a vida privada e o mundo do trabalho. As famílias proletárias viviam em condições extremamente precárias e insalubres, com intensa exploração da mão de obra por parte dos empregadores, que não poupavam nem sequer as crianças do trabalho e das longas jornadas de labor. Contudo, na segunda metade do século XIX, esse cenário se modifica com a emergência dos padrões burgueses, de modo que se passa a ter um sentimento de família, de necessidade da privacidade e de domesticidade, o que faz com que a educação dos filhos e a propriedade privada passem a ser muito valorizadas e com que aos homens fique incumbida a função de trabalho e sustento da família e às mulheres, o cuidado com a casa, os filhos e o marido. (ARIÈS, 1981).

Nesse período, surge a teoria social da medicina, responsável pelas primeiras ações destinadas à saúde dos trabalhadores, e passa-se a considerar a relação dos fatores sociais, culturais e econômicos com a produção da saúde e da doença analisando-se, inclusive, a inter-relação entre condições de trabalho e doenças. Já no século $X X$, inaugura-se a era bacteriológica, na qual se identificam "a participação de vetores ou hospedeiros intermediários na transmissão de doenças e o papel dos portadores sadios na manutenção da cadeia epidemiológica" (BATISTELLA, 2007, p. 43), possibilitando a produção de vacinas e soros imunes e propiciando melhorias nas condições de vida da população.

Com o final da Segunda Guerra Mundial, ganha espaço o modelo de explicação multicausal para os processos de saúde e doença, em que estes passam a ser compreendidos como resultado de múltiplas determinações, havendo diversos fatores que os influenciam e os condicionam. Outrossim, a respeito das famílias, destaca-se que, até os anos 1950, elas são caracterizadas pela hierarquização, por serem conjugais e monogâmicas, sendo elas "a 
estrutura familiar dominante na sociedade capitalista e [que] é frequentemente adotada como norma para todas as outras" (POSTER, 1979, p. 186). Entretanto, a partir de 1960, com o avanço técnico-científico e com o surgimento e a difusão da pílula anticoncepcional, há uma grande transformação no que se refere ao âmbito familiar, uma vez que a mulher passa a ingressar no mercado de trabalho e a zelar por sua liberdade sexual, havendo modificações nas relações de gênero, de sexualidade e de reprodução. (SARTY, 2005).

Em relação à realidade brasileira, destaca-se a década de 1970, na qual, em meio aos movimentos sociais de resistência contra as medidas e os governos da ditadura civil-militar, nasce o movimento pela reforma sanitária, em que se questionam as formas de perceber e pensar as ações em saúde, havendo a incorporação das teorias sociais para fundamentar a problematização dessa realidade e para entender a saúde enquanto um direito de todos. $\mathrm{O}$ modelo de determinação social da doença ganha espaço no sentido de buscar uma explicação mais abrangente para o processo saúde-doença, na qual são articuladas todos os fatores inerentes à sua produção - sejam eles sociais, históricos, culturais, econômicos, ambientais, políticos ou culturais (GIOVANELLA et al., 2012). Ressalta-se a contribuição da teoria marxiana para realizar uma leitura mais ampla dessa realidade, a fim de compreender o processo de saúde-doença e a sua relação com a determinação social.

Em 1986, ocorre a $8^{\circ}$ Conferência Nacional de Saúde, na qual são lançadas as bases para a reforma sanitária e para a construção de um sistema único de atenção, bem como é pensado um conceito amplo de saúde coletiva, que "propõe, desde seu início, a compreensão da integralidade do indivíduo e, portanto, do sujeito/ator social. Inserindo este indivíduo no seu contexto social, busca as manifestações do processo saúde-doença (também determinado socialmente) em seu organismo" (BURLANDY; BODSTEIN, 1998, p. 45). Todo esse processo social e político de luta, de debate e de resistência culminou em uma grande conquista, a qual foi materializada no artigo 196 da Constituição Federal de 1988, que assegura a saúde enquanto um direito de todos e um dever do Estado, devendo o seu acesso ser universal e igualitário.

Para materializar esse acesso universal, o artigo 198 da Constituição regulamenta o Sistema Único de Saúde (SUS), que deve ser descentralizado, propiciar um atendimento integral e contar com a participação da população. Evidencia-se, dessa forma, um modelo de sistema de saúde voltado às necessidades da população, o qual compreende que o processo de saúdedoença tem diversos determinantes e condicionantes e está regulamentado por duas principais legislações: a Lei.$^{\circ} 8.080$ e a Lei n. ${ }^{\circ} 8.142$, ambas de 1990 . Assim, para dar materialidade a esse sistema, ele está regido por princípios como a universalidade, a equidade e a integralidade e possui diretrizes como a hierarquização, a participação popular e a descentralização políticoadministrativa - aspectos regulados em sua forma de operacionalização pelas normas operacionais básicas. (POLIGNANO, 2001). 
DETERMINANTES SOCIAIS E TERRITÓRIO EM SUA INTER-RELAÇ̃̃O

COM AS FAMÍLIAS E OS PROCESSOS DE SAÚDE-DOENÇA

Não obstante, apesar de todos esses avanços no campo do marco legal, verifica-se que a sua materialização e implementação integral ainda figuram como um desafio para a realidade brasileira. Juntamente com a promulgação da Constituição Federal e das legislações que regulamentam o SUS, tem-se o avanço neoliberal, que reatualiza o papel do Estado e preconiza a sua intervenção mínima (BORLINI, 2010). Com as ações de privatização e terceirização e a intensa precarização das relações de trabalho, o capital cria e recria estratégias de exploração que não asseguram o acesso e reduzem e retiram os direitos da população, que acaba por não ter garantido o acesso às condições dignas de vida (ALVES, 2013).

Em um contexto neoliberal, em que o investimento em políticas públicas é ínfimo e os serviços prestados à população mostram-se insuficientes e precarizados, verifica-se que não raras vezes a responsabilidade por atender às demandas por proteção social recai sobre as famílias, que acabam sendo culpabilizadas por não conseguirem prover suas próprias necessidades. Ora, é inegável que as famílias exercem a função de mediar as relações entre os sujeitos e a coletividade, sendo espaço privilegiado de socialização e de história. No entanto,

[...] a sociedade capitalista manipula os indivíduos em prol de sua reprodução, e a família como primeiro meio em que o indivíduo faz parte, além de ter a responsabilidade de educar e moralizar também é responsável pela falha dessa sua função, entretanto, sabemos que a [...] sociedade capitalista impõe regras e padrões quase impossíveis de serem seguidos e, portanto, a instituição família ao não alcançar os objetivos requeridos pelo capitalismo é culpabilizada pelos problemas que afetam a dinâmica da sociedade capitalista (CAVALCANTI et al., 2013, p. 26).

Nesse sentido, é imperativo que sejam implementadas ações que vão de encontro ao ideário neoliberal e que contribuam para o fortalecimento das famílias para que elas, de fato, possam se reconhecer enquanto sujeitos detentores de direitos e consigam assumir o papel de protagonistas nos processos de luta em prol do efetivo acesso às políticas de proteção social. Para isso, tem-se o território enquanto um espaço privilegiado, haja vista que é nele que se concretiza o cotidiano vivido dos sujeitos, onde estes constituem suas relações e suas redes de apoio e de pertencimento, bem como onde acessam - ou não - as condições materiais a uma vida digna. Ou seja, é necessário um olhar atento para cada território singular, pois é nele que se conjugam os determinantes sociais da saúde, sendo a atenção básica uma parceira fundamental nesse processo. 


\section{0 território enquanto categoria no processo saúde-doença}

Ao correlacionar o território sob a luz do processo saúde-doença, fazse necessária a imersão ontológica na categoria em questão. O território, segundo Santos (1999), só pode ser considerado categoria de análise para além do "termo em-si", pois

O território não é apenas o conjunto dos sistemas naturais e de sistemas de coisas superpostas. O território tem que ser entendido como o território usado, não o território em si. 0 território usado é o chão mais a identidade. A identidade é o sentimento de pertencer àquilo que nos pertence. $O$ território é o fundamento do trabalho, o lugar da residência, das trocas materiais e espirituais e do exercício da vida (SANTOS, 1999, p. 2).

Ao ultrapassar os limites geográficos, o território ganha potencialidade ontológica, enquanto espaço onde se estabelece a vida cotidiana, conceituada por Heller (1982) como categoria que abriga "todas as atividades através das quais o homem reproduz a si mesmo para poder reproduzir a sociedade" (1982, p. 194). Marx, nesse sentido, elucida que o homem, modificando a natureza, "ao mesmo tempo modifica sua própria natureza" (1988, p. 202). Esse movimento de modificação mútua da relação homem-natureza, em que um ser em-si, meramente natural, para um ser cada vez mais social, figurando como um ser para-si, é efetivado a partir da práxis social, que se inicia a partir do trabalho e que alicerça a constituição das cidades.

O trabalho, em seu caráter útil-concreto, enquanto "condição da existência do homem" (MARX, 1988, p. 57) no processo de desenvolvimento do ser social, é sempre um ato teleológico, pois o homem "não transforma apenas o material sobre o qual opera; ele imprime ao material o projeto que tinha consciente em mira" (MARX, 1988, p. 142). Em conformidade a isso, o território usado também pode ser considerado em sua relação teleológica, a partir do entendimento de que "os objetos que constituem o espaço geográfico atual são intencionalmente concebidos para o exercício de certas finalidades, intencionalmente fabricados e intencionalmente localizados. A ordem espacial assim resultante é, também, intencional." (SANTOS, 2006, p. 261). Denomina-se, dessa forma, a partir das reflexões de Marx, esse processo de materialização consciente de objetivação:

Na elaboração do mundo objetivo [é que] o homem se confirma, em primeiro lugar e efetivamente, como ser genérico. Esta produção é a sua vida genérica operativa. Através dela a natureza aparece como sua obra e sua efetividade (Wirklichkeit). O objeto do trabalho é portanto a objetivação da vida genérica do homem: quando o homem se duplica não apenas na consciência, intelectual[mente], mas operativa, efetiva[mente], contemplando-se, por isso, a si mesmo num mundo criado por ele (MARX, 2004, p. 85). 
DETERMINANTES SOCIAIS E TERRITÓRIO EM SUA INTER-RELAÇ̃̃O

COM AS FAMILIIAS E OS PROCESSOS DE SAÚDE-DOENÇA

Nessa perspectiva, ao ter como pressuposto as modificações sóciohistóricas da função social da família e das primeiras ações no âmbito da saúde pública no Brasil, pode-se compreender que é no território que esse fenômeno ganha materialidade, o qual se torna indissociável do processo de urbanização tardio da sociedade capitalista brasileira. Segundo Mansanera e Silva (2000), após a abolição da escravatura, tem-se no território brasileiro um processo de incipiente industrialização, repercutindo em novas feições das cidades, do comércio internacional e das correntes imigratórias e, principalmente, na presença de contingentes populacionais "livres" concentrados no espaço urbano, que deram nova complexidade à estrutura social do país. Inicia-se, assim, o fomento de um projeto higienista no Brasil pelos dirigentes republicanos, focalizado no controle higiênico dos portos, na proteção da sanidade da força de trabalho e no encaminhamento de uma política demográfico-sanitária que contempla a questão racial - com o "ideal de branqueamento" do povo brasileiro.

Dessa forma, o discurso médico-higiênico passa a acompanhar o início do processo de transformação política e econômica da sociedade brasileira em uma economia urbano-comercial. Nele, expressa-se o pensamento de uma elite dominante que tinha a intencionalidade de modernizar o país, apropriandose do conceito de higiene para justificar a desigualdade social enquanto "desorganização social e mau funcionamento da sociedade" (MANSANERA; SILVA, 2000, p. 4). Isso gera não apenas um processo de profissionalização da medicina - enquanto exclusiva no processo de cura e controle da doença -, rotulando e desmerecendo resistências e saberes alternativos como ignorância do povo, mas também de culpabilização das classes sociais pobres enquanto produtoras das doenças, cabendo à medicina refletir e atuar sobre seus componentes naturais, urbanísticos e institucionais ao tornar-se instrumento de planejamento urbano: ou seja, as grandes transformações na cidade são justificadas como questão de saúde.

No entanto, as raízes do discurso clínico higienista, se analisadas a partir de seu alicerce macroestrutural, podem ser compreendidas a partir da intenção de apropriação da produção capitalista do território. Esse processo, para lamamoto (2008), ocorre a partir da trindade econômica capital-terratrabalho, que se associa e se desenvolve respectivamente na tríade juro-renda fundiária-salário. Segundo a autora, a propriedade fundiária é um pressuposto histórico e fundamento permanente do regime capitalista de produção, comum a outros modos históricos de se produzir. Entretanto, o capital cria a forma histórica específica de propriedade que lhe convém, valorizando esse monopólio na base da exploração capitalista. Assim, a propriedade privada adquire sua forma permanentemente econômica - despojando-se dos vínculos políticos e sociais anteriores:

A propriedade tem que destruir pouco a pouco, até que ela desapareça, a propriedade do solo, que é a propriedade imediata, primitiva. Deste modo, a riqueza imobiliária (o dinheiro 
e o capital) suplanta a riqueza natural da terra e dos produtos do solo, que conferia ao proprietário prestígio quase mágico e do qual não podia ser privado (LEFEBVRE, 1972, p. 36).

Portanto, a expansão das cidades "dá um valor artificial, colossalmente aumentado ao solo em certas áreas, particularmente nas de localização central" (ENGELS, 1873, p. 11), resultado da aglomeração dos meios de produção e da concentração dos meios de consumo coletivos. Este processo bilateral de industrialização e urbanização - acaba se transformando em condição cada vez mais sine qua non do desenvolvimento econômico das cidades (LOJKINE, 1981). Evidencia-se, assim, a essência abstrata (privada) na qual se estabelecem tanto as relações de produção quanto a práxis social capitalista, que cria, pouco a pouco no cotidiano das cidades, novas necessidades e formas de interação social entre os homens e dos homens com a natureza, a partir do estranhamento (MARX, 2004) da tríade capital-terra-trabalho gerado na sociedade capitalista: "a propriedade privada é, portanto, o produto, o resultado, a consequência necessária do trabalho exteriorizado, da relação externa (äusserlichen) do trabalhador com a natureza e consigo mesmo" (MARX, 2004, p. 87).

Esse processo de estranhamento do território, decorrente da relação homem-natureza condicionada pelo capital, afeta diretamente a organização dos espaços urbanos, estreitando, com isso, "sua qualidade social distintiva (standesunterschied)" (MARX, 2004, p. 50) para dar protagonismo à expansão do potencial físico e econômico do capital imobiliário na construção das cidades. Tal modelo de desenvolvimento pautado na expansão constante gera "periferias pobres e sub equipadas, ao mesmo tempo em que define eixos de expansão das classes média e abastadas, deslocando as centralidades de seus sítios originais" (BALBIM, 2008, p. 1) para espaços adaptados ao padrão de consumo contemporâneo.

A cidade em si, como relação social e como materialidade, torna-se criadora da pobreza, tanto pelo modelo socioeconômico de que é o suporte, como por sua estrutura física, que faz dos habitantes das periferias [...] pessoas ainda mais pobres. A pobreza não é apenas o fato do modelo socioeconômico vigente, mas, também, do modelo espacial (SANTOS, 1996, p. 10).

Na perspectiva do cotidiano dos sujeitos na construção e manutenção objetiva da cidade urbana, os "aspectos da vida social não parecem diretamente determinados pelas relações capitalistas de produção" (BIHR, 1998, p.143). Contudo, a práxis social e a relação do homem com o território usado acabam aprisionadas "a um fragmento do real, à tendência espontânea de orientar-se para seu eu particular" (PATTO, 1993, p. 125), criando objetivações em si, e não realidades para si. 


\begin{abstract}
Na medida em que o trabalho estranhado 1) estranha do homem a natureza, 2) [e o homem] de si mesmo, de sua própria função ativa, de sua atividade vital, ela estranha do homem o gênero [humano]. Faz-Ihe da vida genérica apenas um meio da vida individual. Primeiro, estranha a vida genérica, assim como a individual. Segundo, faz da última em sua abstração um fim da primeira, igualmente em sua forma abstrata e estranhada (MARX, 2004, p. 85).
\end{abstract}

A redução da vida genérica do homem a um meio de vida individual concretiza-se por meio do "processo de apropriação capitalista da práxis social" (BIHR, 1998), em que os imperativos da reprodução do capital submetem as relações sociais - e não mais somente as relações de produção - à lógica da "equivalência de troca mercantil" (BIHR, 1998, p. 144). Assim, as objetivações em-si podem ser vistas não só como estando cada vez permeadas pela lógica da produção capitalista, mas também como objetivações cunhadas de ideologia, que influenciam a concepção dos territórios e da saúde. Nesse sentido, compreende-se que a lógica de culpabilização das famílias quanto a suas condições de saúde - sobretudo das que se encontram em situação de vulnerabilidade social - é gerada não somente pelas raízes higienista e elitista nas quais o conceito de saúde foi constituído no país, mas também pelo processo de mercantilização da saúde e de estranhamento da categoria território na sociabilidade capitalista, o qual desloca o processo saúde-doença de sua materialidade socioespacial e de seus determinantes sociais.

\title{
4 Os determinantes sociais: entre conceitos e dimensões de atuação
}

Segundo Buss e Pellegrini (2007), há, na contemporaneidade, diversas definições de determinantes sociais de saúde (DSS) que expressam, de maneira geral, o conceito de que as condições de vida e de trabalho dos sujeitos e dos grupos da população estão relacionadas com sua situação de saúde-doença. Nessa perspectiva, apresentam-se quatro exemplos de definições: para a Comissão Nacional sobre os Determinantes Sociais da Saúde (CNDSS), os DSS estão associados a fatores sociais, econômicos, culturais, étnicos ou raciais, psicológicos e comportamentais; já para a Organização Mundial da Saúde (OMS), os DSS são relacionados às condições sociais em que as pessoas vivem e trabalham; para Krieger (2001), por sua vez, os determinantes em saúde são vistos como "fatores e mecanismos através dos quais as condições sociais afetam a saúde e que potencialmente podem ser alterados através de ações baseadas em informação" (apud BUSS; PELLEGRINI, 2007, p. 78); enquanto que, para Tarlov (1996), os DSS são as características sociais em meio às quais a vida transcorre.

Independentemente das variadas concepções, torna-se inegável o avanço no estudo da correlação entre a organização social de uma sociedade e sua situação de saúde. Esse avanço é particularmente marcante no estudo das 
iniquidades em saúde, ou seja, "daquelas desigualdades de saúde entre grupos populacionais que, além de sistemáticas e relevantes, são também evitáveis, injustas e desnecessárias" (WHITEHEAD, 2000 apud BUSS; PELLEGRINI, 2007, p. 80), havendo três gerações em relação a elas:

A primeira geração se dedicou a descrever as relações entre pobreza e saúde; a segunda, a descrever os gradientes de saúde de acordo com vários critérios de estratificação socioeconômica; e a terceira e atual geração está dedicada principalmente aos estudos dos mecanismos de produção das iniqüidades ou, para usar a expressão de Adler, está dedicada a responder à pergunta: como a estratificação econômico-social consegue "entrar" no corpo humano? (BUSS; PELLEGRINI, 2007, p. 80).

Sob essa ótica, entende-se que o desafio de compreender os DSS se encontra em apreendê-los para além de uma mera relação sistêmica de causa-efeito, percebendo-os como um complexo de mediações entre fatores individuais e estruturais: ou seja, trata-se de compreender a particularidade em que os DSS se materializam em dado território - permitindo a identificação de onde e como devem ser feitas as intervenções, com o objetivo de reduzir as iniquidades de saúde. Buss e Pellegrini (2007) apontam, a partir dos modelos de Dahlgren e Whitehead e de Diderichsen, quatro níveis de identificação para intervenções de políticas, os quais visam minimizar os diferenciais de DSS originados pela posição social dos sujeitos e grupos.

O primeiro nível relaciona-se aos fatores comportamentais e de estilos de vida, abarcando o pressuposto de que a modificação de comportamentos de risco individuais está interligada a compreensão das normas culturais que os influenciam. Nesse sentido, são necessárias políticas de abrangência populacional por meio de programas educativos e comunicação social, focalizados na conscientização dos sujeitos. Já o segundo nível abrange o âmbito da comunidade e suas redes de relações, percebendo essa interação social como pressuposto fundamental para a promoção e proteção da saúde individual e coletiva. Nessa esfera, incluem-se políticas potencializadoras de redes de apoio, fortalecendo o controle social, especialmente dos grupos em situação de vulnerabilidade, em ações coletivas para a melhoria de suas condições de saúde e bem-estar.

Já o terceiro nível se refere às políticas que possuem ações direcionadas às condições materiais e psicossociais sob as quais os sujeitos vivem, na perspectiva de assegurar o acesso aos serviços de forma intersetorial entre as diferentes instituições e de estabelecer mecanismos que permitam uma ação integrada. O quarto nível, por sua vez, refere-se à atuação no âmbito dos macrodeterminantes, por meio de políticas macroeconômicas que visem à promoção de um desenvolvimento sustentável, à redução de desigualdades sociais e econômicas e a redução de violências e seus efeitos sobre a sociedade. 
DETERMINANTES SOCIAIS E TERRITÓRIO EM SUA INTER-RELAÇÃO

COM AS FAMÍLIAS E OS PROCESSOS DE SAÚDE-DOENÇA

Tais níveis de atuação na promoção de políticas que visam à equidade em saúde se materializam a partir do conhecimento e da intervenção técnicooperativa dos profissionais com a participação ativa dos sujeitos, sob o alicerce da Política Nacional de Atenção Básica (PNAB), que compreende o âmbito da família enquanto primeiro nível de atenção no SUS. Nesse sentido, como estratégia primordial para a organização e o fortalecimento da atenção básica, existem os princípios de universalidade, acessibilidade, vínculo, continuidade do cuidado, integralidade da atenção, humanização, equidade e participação social. No entanto, esses fundamentos da política só se materializam na realidade concreta das famílias se articulados com seu cotidiano e seu território. Para isso, é fundamental que as ações em saúde não somente realizem a cobertura do espaço geográfico de determinada comunidade, mas também sejam parte integrante da experiência socioespacial dos sujeitos que lá vivem, compreendendo a particularidade relacional dos processos de saúde-doença desses sujeitos com os determinantes em saúde que lhe são transversais.

Em meio a essa reflexão, destaca-se a discussão acerca do papel das famílias no âmbito das políticas públicas, as quais não raras vezes, em uma perspectiva familista (PEREIRA, 2013), são culpabilizadas e demandadas a atender e a prover as necessidades de seus pares, como se fosse inerente a elas o exercício da função de cuidar e proteger. Todavia, anteriormente a isso, é fundamental que se compreenda que a capacidade de cuidado e de proteção da família é diretamente relacionada aos cuidados e à proteção que lhe são garantidos por meio das políticas sociais (MIOTO, 2003), sendo este um dever do Estado. Assim, verifica-se que, de fato, a atenção básica é um espaço de atuação privilegiado para a promoção e a proteção da saúde, mas, para isso, é fundamental que sejam considerados nessa relação o território e todos os determinantes sociais que impactam no processo de saúde-doença, bem como que se tenha em perspectiva um conceito amplo não só de saúde, mas também de famílias.

\section{Considerações finais}

As famílias vêm assumindo as mais variadas configurações, de forma que a sociedade como um todo deve estar preparada para compreendê-la dentro desse processo histórico, superando concepções reducionistas que alimentam preconceitos e materializam violações. Nesse sentido, torna-se um desafio para a criação, implementação e avaliação das políticas públicas assegurar, dentro de um contexto de privatização e comercialização da saúde, uma atenção integral que de fato promova o acesso à proteção social. Assim, é fundamental que se compreendam os processos sócio-históricos que permeiam a construção de um conceito tanto de famílias quanto do processo de saúdedoença, que não podem ser deslocados da análise conjuntural e estrutural do desenvolvimento tardio da sociedade capitalista no contexto brasileiro, bem como dos processos de desigualdade que dela resultam. 
A análise e a problematização dessas desigualdades correlacionadas ao processo de saúde-doença, ou seja, suas iniquidades, são primordiais para realizar uma leitura ampla e mediar o processo dialético entre singular-particular-universal, sem que ocorra apenas uma transferência de responsabilidade por atender as demandas em cuidado para as famílias, culpabilizando-as e sobrecarregando-as. Tal emblema se potencializa, majoritariamente, no constructo social e ideológico da incapacidade do Estado de administrar o processo saúde-doença, alicerçado sob o discurso da eficácia do modelo privatista de saúde, encobrindo as questões de agravo de doença enquanto expressões do próprio acirramento da questão social.

Em meio a esse contexto, tem-se o território enquanto espaço privilegiado, no qual se manifestam mais claramente os determinantes sociais da saúde, bem como onde se tem a atuação da atenção básica, em uma perspectiva descentralizada e integralizada. É preciso, assim, que o território seja pensado e compreendido para além de seu espaço geográfico, sendo visto como um espaço vivido por sujeitos, no qual estes produzem e reproduzem suas relações e por meio do qual são condicionados e também condicionantes.

Indo ao encontro dessa reflexão, é primordial que se desenvolvam ações no sentido de identificar os determinantes sociais de cada território, a fim de possibilitar que "mais que ser reconhecida como instância de cuidado e proteção, a família, deve ser reconhecida como instância a ser cuidada e protegida, enfatizando a responsabilidade pública" (MIOTO, 2004, p. 3) -, ainda que em um contexto neoliberal de retração do Estado. Entender as pessoas como sujeitos de direitos é o primeiro passo em um caminho propulsor para que as famílias possam se empoderar para serem partícipes ativos dos processos decisórios e de fomento em prol de seus direitos por uma política pública de saúde coletiva e universal que promova e assegure uma atenção integral a toda a população, reiterando seus espaços coletivos e comunitários para além das questões socioeconômicas e da delimitação geográfica.

\section{Referências}

ALVES, G. Crise estrutural do capital, maquinofatura e precarização do trabalho: a questão social no século XXI. In: Textos \& Contextos, (Porto Alegre), v. 12, n. 2, p. 235 - 348, jul./dez. 2013. Disponível em: <http:// revistaseletronicas.pucrs.br/ojs/index.php/fass/article/view/15882/10735>. Acesso em: 07 abr. 2017.

ARIÈS, P. A história social da criança e da família. Rio de Janeiro: Zahar, 1981.

BATISTELLA, C. Saúde, Doença e Cuidado: complexidade teórica e necessidade histórica. In: FONSECA, A. F.; CORBO, A. M. D’A. (orgs.). $\mathbf{O}$ território e o processo saúde-doença. Rio de Janeiro: EPSJV/FIOCRUZ, 2007. p. 25-50.

BALBIM, R. Reabilitação de áreas urbanas centrais. 2008 . Ano 5 . Edição 46. Disponível em:<http://www.ipea. gov.br/desafios/index.php?option=com_content\&view=article\&id=998:catid=28\&ltemid=23/>. Acesso em: 08 abr. 2017.

BIHR, A. A crise da sociabilidade. In __. Da grande noite à alternativa - o movimento europeu em crise. São Paulo: Boitempo, 1998.

BORLINI, L. M. Há pedras no meio do caminho do SUS: os impactos do neoliberalismo na saúde do Brasil. In: 
DETERMINANTES SOCIAIS E TERRITÓRIO EM SUA INTER-RELAÇÃO

COM AS FAMÍLIAS E OS PROCESSOS DE SAÚDE-DOENÇA

Textos \& Contextos, (Porto Alegre), v. 9, n. 2, p. 321 - 333, ago./dez. 2010. Disponível em: <http:// revistaseletronicas.pucrs.br/ojs/index.php/fass/article/viewFile/7697/5799>. Acesso em: 07 abr. 2017.

BURLANDY, L.; BODSTEIN, R. C. A. Política e saúde coletiva: reflexão sobre a produção científica (1976-1992). In: Cadernos de Saúde Pública, vol. 4, n. 3. Rio de Janeiro: Rio de Janeiro, 1998. Disponível em: <http:// www.scielo.br/pdf/csp/v14n3/0091.pdf>. Acesso em: 02 abr. 2017.

BUSS, P. M.; PELLEGRINI FILHO, A. A saúde e seus determinantes sociais. IN: Physis, Rio de Janeiro, vol. 17, n. 1, p. 77-93, Abr.. 2007. Disponível em: <http://www.scielo.br/scielo.php?script=sci_arttext\&pid=S010373312007000100006\&lng=en\&nrm=iso>. Acesso em: 05 abr. 2017.

CAVALCANTI, K. M. G.; SILVA, L. B.; SANTOS, L. L. F.; LINS, M. A. T.; SANTOS, V. S. B. A centralidade da família nas políticas sociais brasileiras. In: Cadernos de Graduação - Ciências Humanas e Sociais Fits (Maceió), vol. 1, n. 2, p. 23-35, maio de 2013. Disponível em: <https://periodicos.set.edu.br/index.php/fitshumanas/article/ viewFile/698/386>. Acesso em: 02 abr. 2017.

ENGELS, Frederich. Sobre a questão da habitação. 1873. Disponível em: <http://resistir.info/livros/engels_q_ habitacao.pdf/>. Acesso em: agosto de 2015.

GIOVANELla L.; LOBATO L. V. C.; NORONHA, J. C.; CARVALHO, A. I. Políticas e Sistema de Saúde no Brasil. $2^{a}$ Edição revista e ampliada. Rio de Janeiro: Editora Fiocruz; 2012.

HELLER, A. O homem do renascimento. Tradução de Conceição Jardim e Eduardo Nogueira. Lisboa. Presença, 1982.

Sociologia de la vida cotidiana. Traducao de J. F. Yvars. 3 ed. Barcelona, 1991.

IAMAMOTO, M. V. Serviço Social em tempos de capital fetiche: capital financeiro, trabalho e questão social. 2 ed. São Paulo: Cortez, 2008.

KOSIK, K. Dialética do concreto. 2. ed. Rio de Janeiro: Paz e Terra, 1989.

LEFEBVRE, H. O pensamento marxista e a cidade. Editora Ulisseia. Tradução Maria Idalina Furtado, 1972.

LOJKINE, J. O Estado Capitalista e a Questão Urbana. São Paulo: Martins Fontes, 1981

LUKÁCS, G. Ontologia do ser social. Os princípios ontológicos fundamentais de Marx. Tradução de Carlos Nelson Coutinho. São Paulo: Livraria Ciências Humanas, 1979.

. Estetica I: La peculiaridad de lo estético. Barcelona, México, DF: Grijalbo, 1967.

As bases ontológicas do pensamento e da atividade do homem. Revista Temas de Ciências Humanas, n 4, São Paulo: Ciências Humanas, 1978.

MANSANERA, Adriano R; SILVA, Lúcia Cecília da. A influência das ideias higienistas no desenvolvimento da psicologia no Brasil. Revista Psicologia em Estudo. DPI/CCH/UEM, v.5, n.1, 2000, p. 115-137.

MARX, K. Manuscritos econômico-filosóficos. Editora Boitempo, São Paulo, 2004

O Capital. São Paulo, Nova Cultural, Volume I, 1988.

MASTROMAURO, G. C. Surtos epidêmicos, teoria miasmática e teoria bacteriológica: instrumentos de intervenção nos comportamentos dos habitantes da cidade do século XIX e início do XX. In: Anais do XXVI Simpósio Nacional de História - ANPUH. São Paulo, julho 2011. Disponível em: <http://www.snh2011. anpuh.org/resources/anais/14/1300472386_ARQUIVO_Mastromauro.pdf>. Acesso em: 03 abr. 2017

MIOTO, R. C. T. A centralidade da família na política de assistência social: contribuições para o debate. In: Revista de Políticas Públicas, São Luís - Maranhão, v. 8, p. 133-143, 2004. Disponível em: <http://www. periodicoseletronicos.ufma.br/index.php/rppublica/article/view/3756>. Acesso em: 07 abr. 2017.

PATTO, Maria Helena Souza. O conceito de cotidianidade em Agner Heller e a Pesquisa da Educação. Perspectivas, São Paulo, 16: 119-141, 1993

PEREIRA, Camila Potyara. Proteção social no capitalismo: contribuições à crítica de matrizes teóricas e ideológicas conflitantes. 2013. xiii, 307 f., il. Tese (Doutorado em Política Social)—Universidade de Brasília, Brasília, 2013.

POLIGNANO, M. V. História das políticas de saúde no Brasil: uma pequena revisão. Minas Gerais: Universidade Federal de Minas Gerais, 2001. Disponível em: <www.medicina. ufmg.br/internatorural/arquivos/ 
mimeo23p.pdf>. Acesso em: 02 abr. 2017.

POSTER, M. Teoria Crítica da Família. Rio de Janeiro: Zahar, 1979.

RODRIGUES, A. A. ABECHE, Regina Peres Christofolli. As implicações da família contemporânea no processo de identificação do adolescente. In: Simpósio Internacional do Adolescente, 2, 2005, São Paulo. Disponível em: <http://www.proceedings.scielo.br/scielo.php?script=sci_ arttext\&pid=MSC0000000082005000200069\&Ing=en\&nrm=abn>. Acesso em: 05 abr. 2017.

SANTOS, M. A urbanização Brasileira. São Paulo: Hucitec, 1996.

O dinheiro e o Território. GEOgraphia. Revista da Pós- Graduação em Geografia, UFF. Rio de Janeiro, no1, 1999.

A natureza do espaço. Técnica e Tempo, Razão e Emoção - 4. ed. 2. São Paulo: Editora da Universidade de São Paulo, 2006.

SARTI, C. A. Famílias enredadas. In: ACOSTA, A. R.; VITALE, M. A. Família: redes, laços e políticas públicas. São Paulo: Cortez, 2005.

SOUZA, E. C. L. L.; RODRIGUES, M. A. M. Família e paternidade: o papel do pai na criação dos filhos. 2007. Disponível em: <http://www.abrapso.org.br/siteprincipal/anexos/AnaisXIVENA/conteudo/pdf/trab_ completo_225.pdf>. Acesso em: 03 abr. 2017.

TARLOV, A. Social Determinants of Health: the sociobiological translation. In: Paulo Marchiori Buss e Alberto Pellegrini Filho PHYSIS: Revista Saúde Coletiva, Rio de Janeiro, 17(1):77-93, 2007 BLANE, D.; BRUNNER,E.; WILKINSON, R. (Eds.). Health and Social Organization. London: Routledge. p. 71-93, 1996. 